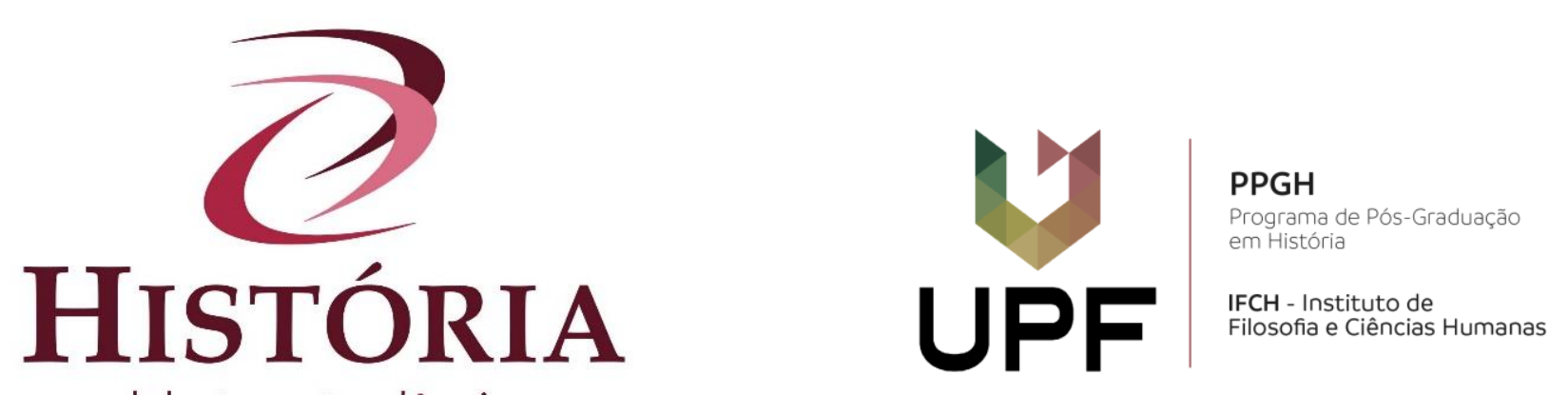

\author{
debates e tendências
}

\title{
Por entre jornais, documentos e fotos: a tessitura da história de São
}

\section{Leopoldo}

\section{Among newspapers, documents and photos: the writing of the history of São \\ Leopoldo \\ Por entre periódicos, documentos y fotos: la escritura de la historia de São Leopoldo}

Isabel Cristina Arendt ${ }^{\mathrm{i}}$

Eloisa Helena Capovilla da Luz Ramos ${ }^{\text {ii }}$

\begin{abstract}
Resumo: O artigo tem por objetivo homenagear a figura de Germano Oscar Moehlecke. Comerciante de origem leopoldense, no Rio Grande do Sul (Brasil), foi fundador e membro atuante do Museu Histórico Visconde de São Leopoldo (MHVSL), inaugurado em 1959. Foi também fundador e membro permanente do Instituto Histórico de São Leopoldo (IHSL), inaugurado em 1975 no contexto do Biênio da Colonização e Imigração no Rio Grande do Sul. Neste evento, foi Presidente da Comissão em nível municipal. Além destes aspectos, o texto aborda o interesse de Germano Moehlecke pela história de São Leopoldo, escrita a partir de fotografias e documentos oficiais. Também analisa a produção escrita do autor. A intenção de Moehlecke, deduzimos, era construir uma outra história para a cidade e seus moradores, o que conseguiu com uma produção embasada nas fontes existentes no MHVSL, as quais queria tornar visíveis. Para dar conta da trajetória do historiador leopoldense, buscamos apoio também em seus dados pessoais, inserindo-os em seu tempo e em seu espaço. A conclusão a que chegamos, parcial, ainda, é que Germano Oscar Moehlecke foi uma importante liderança cultural na cidade de São Leopoldo pelos lugares que ocupou e pelo legado cultural que deixou.
\end{abstract}

Palavras-chave: Escrita da História. Patrimônio cultural. São Leopoldo.

Abstract: The aim of this study is to introduce Germano Oscar Moehlecke, trader, founder and active member of the Museu Histórico Visconde de São Leopoldo (MHVSL) - Viscount of São Leopoldo Historical Museum, in Rio Grande do Sul (Brazil), inaugurated in 1959 and the Instituto Histórico de São Leopoldo (IHSL) - São Leopoldo Historical Institute, inaugurated in 1975, during the Settlement and Immigration Biennial, becoming local Commission President. This study approaches his interest in the history of his town, São Leopoldo. It was formerly presented in chronicles and essays about the daily life using photographs, documents, and later a dozen books released arising from these materials and other historical records researched around the State. It was Moehlecke's intention, as percieved, to construct another history for the city and the residents, which was achieved based on the existing writings found especially at MHVSL. In order to accomplish the Leopoldense historian's path in that period, all the personal 
data collected were inserted in his time and space. In conclusion, Germano Oscar Moehlecke was an important cultural leader in the city of São Leopoldo, not only for the role he performed, but also for the cultural legacy he left.

Key words: Cultural legacy. São Leopoldo. Writing of History

Resumen:El artículo tiene por objetivo homenajear la figura de Germano Oscar Moehlecke. Comerciante de origen leopoldense (Río Grande del Sur, Brasil), fue fundador y miembro actuante del Museu Histórico Visconde de São Leopoldo (MHVSL), inaugurado en 1959. Fue también fundador y miembro permanente del Instituto Histórico de São Leopoldo (IHSL), inaugurado en 1975 en el contexto del Bienio de la Colonización e Inmigración en el Río Grande del Sur. En este evento, fue presidente de la Comisión a nivel municipal. Además de estos aspectos, el texto aborda el interés de Germano Moehlecke por la historia de São Leopoldo, escrita a partir de fotografías y documentos oficiales. También analiza la producción escrita del autor. La intención de Moehlecke, deducimos, era construir otra historia para la ciudad y sus habitantes, lo que logró con una producción basada en las fuentes existentes en el MHVSL, las cuales quería hacer visibles. Para dar cuenta de la trayectoria del historiador leopoldense, buscamos apoyo también en sus datos personales, insertándolos en su tiempo y en su espacio. La conclusión a la que llegamos, parcial aún, es que Germano Oscar Moehlecke fue un importante liderazgo cultural en la ciudad de São Leopoldo por los lugares que ocupó y por el legado cultural que ha dejado.

Palabras-clave: Escritura de la Historia. Patrimonio cultural. São Leopoldo.

\section{Introdução}

Nesse texto queremos destacar a figura de Germano Oscar Moehlecke por sua atuação em prol do patrimônio histórico e cultural de São Leopoldo por mais de cinquenta anos. Para atingir este objetivo, nos perguntamos, em primeiro lugar o que levaria um jovem comerciante a se interessar pela história de sua cidade no início dos anos de 1940 ? Seria o pendor para a literatura e a crônica, que junto com alguns conhecimentos de psicologia, como aventa no texto em que fala de sua trajetória de vida, lhe permitiram perceber os tipos sociais com os quais se defrontava diuturnamente e sobre eles escrever? Seria uma preocupação com a declaração de guerra feita pelo Brasil à Alemanha e aos outros países do Eixo, em 1942, durante a II Guerra Mundial e as consequências que daí poderiam advir para a sua cidade? $\mathrm{Ou}$, então, um motivo mais sensível ligado à necessidade que sentiu de registrar em pequenos textos jornalísticos a vida cotidiana da cidade de São Leopoldo quase sempre a partir de fotografias e de documentos? Poderia ser, ainda, o desejo de contribuir para a escrita de uma outra versão da história da cidade e de seus moradores? Ou seriam todos estes motivos juntos? De antemão avisamos que esta é uma resposta que não temos pronta. Tudo que podemos fazer é intuir esta resposta a partir de vários indícios entre os quais os escritos de nosso personagem. 
Ao propormos traçar a trajetória intelectual de Germano Oscar Moehlecke, buscamos os seus dados pessoais para inseri-lo no seu tempo. Nosso personagem nasceu em São Leopoldo, no dia 23 de outubro do ano de 1922, e faleceu na mesma cidade em 27 de dezembro de 2016.

Figura 1 - Germano Moehlecke

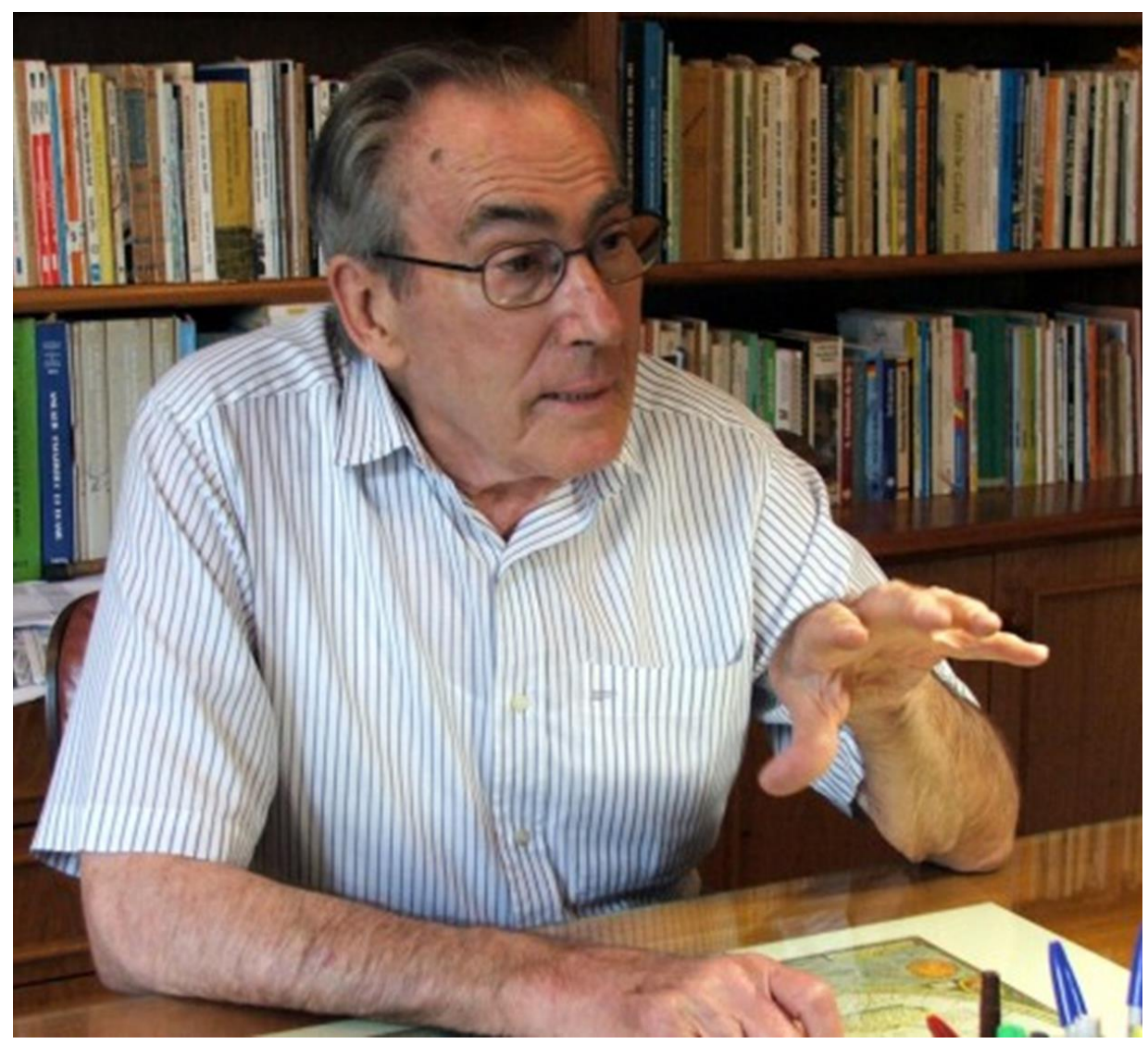

Fonte: Morre o historiador Germano Moehlecke aos 94 anos. In: Jornal Vale dos Sinos (VS), Obituário, São Leopoldo, 27.12.2016. Disponível em:

<http://www.jornalvs.com.br/_conteudo/2016/12/noticias/regiao/2051316-morre-o-historiador-germanomoehlecke.html . Acesso em: set. 2018.

Cursou o primário no Colégio Elementar de São Leopoldo e fez o curso secundário no Colégio Marista, onde fez também o Curso Comercial. Era um "autodidata aplicado [que] participou de inúmeros cursos de extensão e aperfeiçoamento, tendo lecionado por largo tempo". Foi o que escreveu na orelha esquerda de um de seus livros (1986). “As práticas de produção de si”, como nos diz Gomes (2004, p. 11),

podem ser entendidas como englobando um diversificado conjunto de ações, desde aquelas mais diretamente ligadas à escrita de si propriamente dita [...] até a da constituição de uma memória de si, realizada pelo recolhimento de objetos (...), com ou sem a intenção de resultar em coleções. É o caso das fotografias, dos cartões-postais e de uma série de objetos do cotidiano, que passam a povoar e a transformar o espaço privado da casa, do escritório, etc. em um "teatro da memória” (GOMES, 2004, p.11). 
Sob este ponto de vista, estamos diante de um homem que "dizia de si" ao colecionar e publicar fotos e cartões postais assim como escrever sobre a cidade de São Leopoldo.

\section{O começo de tudo}

Nas atividades ligadas à cultura, Germano Oscar Moehlecke liderou, com outros companheiros, o movimento da criação do Museu Histórico Visconde de São Leopoldo inaugurado em 1959, do qual foi presidente por longos anos e, mais tarde, participou ativamente da criação do Instituto Histórico de São Leopoldo (1975). Como fundador e sócio efetivo do mesmo, ocupou, até sua morte, a cadeira de n. 07, cujo Patrono era o arquiteto/engenheiro João Grünewald.

Ao longo dos anos 1960 e 1970 Germano Moehlecke foi presença constante no Museu, mas foi, sobretudo, presença reconhecida na cidade por sua atuação no campo da cultura. Resultado direto dessa ação cultural que vinha desenvolvendo, coube-lhe ocupar um cargo político na cidade, em abril de 1965: foi nomeado Presidente do Conselho Municipal de Turismo (COMTUR) de São Leopoldo, cargo criado pela Lei municipal n. 1317 de 31/12/1964. Coroando este reconhecimento, coube-lhe, ainda, a Presidência da Comissão Municipal do Sesquicentenário da Imigração alemã, durante o Biênio da Colonização e Imigração, nos anos de 1974/75, sobre a qual falaremos adiante, mas é importante que se diga que tal representação o colocava no centro das atividades realizadas em São Leopoldo em torno do Biênio da Colonização e Imigração.

No final dos anos 1990 e início dos anos 2000, Moehlecke voltou para a Secretaria da Cultura do Município, atuando junto ao Museu do Trem, onde permaneceu por mais de dez anos, segundo relatou em texto (ARENDT; WITT, 2011, p. 85) sobre sua trajetória de vida e sua produção histórica.

A par destas ações de inserção na comunidade, foi ainda membro da Academia de Letras Municipais do Brasil, Sócio-correspondente do Círculo de Pesquisas Literárias do Rio Grande do Sul e Sócio fundador do Centro Literário de São Leopoldo. Nestes espaços, inseriu-se também pela escrita de romances como "A mulher que não sabia amar" (1979), entre outros.

No desdobramento de sua atuação na cidade de São Leopoldo, destacamos a importante colaboração na criação do Museu Histórico Visconde de São Leopoldo, inaugurado em 20 de setembro de 1959, mas pensado desde o início dos anos 1950. 
Juntamente com Telmo Lauro Müller e Kurt Schmeling formaram o trio que liderou o movimento. Até então sua participação na vida social de São Leopoldo estava ligada mais ao comércio e às crônicas publicadas nos jornais, nos quais atuava desde o ano de 1943. No contexto da criação do Museu, Moehlecke posicionou-se a favor da construção de um Museu Histórico Social no Município de São Leopoldo, ideia defendida no jornal Correio de São Leopoldo. Tratava-se, segundo ele, de um museu voltado à "história local". Mas, ao assinar a matéria com pseudônimo [Noumenon], Germano Oscar Moehlecke poderá ter feito uma jogada dupla, para se proteger, porque, se defendesse a construção de um museu da imigração alemã, no jogo de palavras e sentimentos do período, essa atitude poderia ser tomada como uma forma de driblar a vigilância dos representantes da "brasilidade" e da construção da identidade Nacional. Assim, a proposta de um museu que não fosse necessariamente voltado para a imigração nos leva a pensar, concordando com Weber, que houvesse aí um movimento cauteloso (WEBER, 2013, p. 6) por parte do autor. Nessa época [pós Segunda Guerra Mundial e Campanha de Nacionalização], os sentimentos de exaltação da brasilidade ainda estavam muito presentes e poderiam interferir no processo de criação de um museu voltado para a etnia alemã. É pertinente lembrar aqui o que nos diz José Carlos Reis (1999) sobre a escrita da história. Para ele

Toda interpretação, que é uma atribuição de sentido ao vivido, se assenta sobre um "mirante temporal", um ponto de vista, em um presente - vê-se a partir de um lugar social e um tempo específicos [...]. Cada presente seleciona um passado que deseja e lhe interessa conhecer. A história é necessariamente escrita e reescrita a partir das posições do presente, lugar da problemática da pesquisa e do sujeito que a realiza. (REIS, 1999, p. 9).

Do ponto de vista da análise histórica, tendo presente o que disse Reis (1999) e tendo presente o tempo histórico da metade do século XX (anos 1950/1960) entendemos a ação de Moehlecke, quer na criação de um museu da imigração, quer na escrita da história de São Leopoldo. Não havia de sua parte uma predileção pela cultura alemã em detrimento das outras etnias, já que o autor não privilegiava a etnicidade, mas as ações de homens e mulheres na escrita que fazia. Talvez a atividade comercial tenha contribuído para esculpir o perfil de Germano Moehlecke. E é nesse sentido que queremos retomar a atividade principal de nosso homenageado, lembrando que ele era um comerciante de 'grosso trato', atividade na qual permaneceu por mais de meio século (57 anos). Ao juntála à atividade-mor, a de cronista e escritor das coisas da cidade e seu entorno, Germano Oscar Moehlecke se revelou um homem que olhava para São Leopoldo como quem olhava para um "tesouro" que precisava ser mostrado a todos para não correr o risco de se perder. Esta atitude se dará a ver mais claramente a partir da leitura da documentação 
histórica da Câmara Municipal de São Leopoldo, já depositada no Museu. Agora Germano Moehlecke cuidava, preservava e lia a história de São Leopoldo através dos documentos e das imagens. Isto vai se refletir em inúmeros livros e artigos em jornais. Diz ele:

A nossa intenção, ao reunir numa brochura essa colaboração para jornais, é trazer para os interessados na nossa história regional uma diversificada abordagem, ora séria e árida, ora divertida e pitoresca do nosso passado, permitindo ao leitor escolher o capítulo que mais lhe agradar à disposição do momento. (MOEHLECKE, 1978, p. 9, grifo nosso).

Numa outra publicação, de 1986, nosso autor vai alertar que:

Dentro de nosso modo de entender a divulgação histórica, mostramos o documento em sua forma integral, em sequência quase cronológica, sem grandes interpretações, para permitir que cada leitor tire suas próprias conclusões. Nossa esperança, com essa pesquisa, é termos dado mais uma contribuição para o conhecimento de nossa história. (MOEHLECKE, 1986, p. 12, grifo nosso).

Em outros momentos, como em 1997, o livro produzido por Moehlecke resultou de crônicas escritas sobre a cidade, oriundas dos jornais locais e da Capital. Sobre sua escrita disse:

Este livro é resultado de uma coleção de artigos-crônicas de jornal, abordando múltiplas facetas da história de São Leopoldo [...]. Nossos capítulos são acompanhados de numerosas ilustrações[...]. A exposição segue com fidelidade os documentos e demais fontes primárias [...], valorizando a nossa informação e dando-lhe valor histórico. (MOEHLECKE, 1997, p. 5, grifo nosso).

Quando escreveu sobre sua trajetória como historiador, sobre a sua produção historiográfica, Germano Moehlecke lembrou que "desde outubro de 1943 até hoje não parei de publicar. E sempre tendo como tema central a cidade de São Leopoldo”. (MOEHLECKE, 2011b, p. 83, grifo nosso).

\section{Um legado cultural para a cidade}

A escrita que Germano Oscar Moehlecke produziu nos permitiu dizer que ele foi um homem que se constituiu como historiador a partir de seu lugar social, de seu tempo e com as influências desse tempo. E a partir daí buscou reescrever a história da cidade e, às vezes, da antiga região que formava a Colônia Alemã de São Leopoldo. É neste contexto, então, que surge a sua vontade de preservar a memória local através de uma herança cultural representada por cerca de dez livros, inúmeros artigos em Anais do IHSL e centenas de textos publicados nos jornais. Ou seja, nos legou um patrimônio cultural de inestimável valor pelo seu conteúdo, porque o patrimônio, em sua origem, é herança. São bens deixados para os herdeiros, quase sempre representados por bens de natureza 
material. Mas, nesse caso, falamos da herança escrita de nosso personagem, de livros e outros textos que podem ser manuseados por todos os que quiserem estudar a cidade de São Leopoldo. Eles podem ser apropriados por todos aqueles que tiverem interesse em conhecer a cidade, sua cultura e seu passado. As fontes que deram suporte ao seu trabalho com a história foram encontradas em muitos lugares, mas, sobretudo no acervo do Museu Histórico Visconde de São Leopoldo que é, também, mais um patrimônio cultural dos leopoldenses. Ao receber a documentação da antiga Câmara e depois Intendência, o Museu transformar-se-ia numa espécie de arquivo histórico local e possibilitaria a seu Presidente a leitura destes papéis e a produção daí decorrente.

É nesse sentido que destacamos a principal faceta do trabalho de Germano Oscar Moehlecke: a de narrador da sua cidade. Ao fazer esse movimento narrativo, iluminou também a sua forma de produzir o conhecimento histórico através de papéis oficiais e de fotografias. Para ele, como procuramos mostrar em excertos nas páginas anteriores, a verdade histórica estava nessas fontes, imprescindíveis para a sua produção historiográfica. Nesse sentido, minimizava a análise dessas mesmas fontes, deixando essa tarefa a cargo dos seus leitores. Poderíamos dizer sob esta perspectiva que Germano Moehlecke era também um historiador tradicional.

Seu primeiro livro publicado e já referenciado foi $O$ vale do Sinos era assim. Ele foi produzido pela empresa Rotermund, de São Leopoldo, no ano de 1978 e faz um panorama documental e visual do Vale do Rio dos Sinos, da criação da vila e depois cidade em torno desta via fluvial e de como se organizava a vida na colônia e depois cidade entre os anos de 1824 e 1930.

Um outro trabalho de pesquisa de fôlego, desenvolvido por Moehlecke foi executado ao ensejo do Sesquicentenário da Revolução Farroupilha. No texto $O s$ imigrantes alemães e a Revolução Farroupilha, lançado em 1986 e bancado pelo próprio autor, fez uma varredura em documentos oficiais e buscou desvendar a participação dos alemães no evento, a partir de dúvidas que possuía sobre o assunto. Nesse trabalho, sobressai-se uma outra preocupação de Germano Moehlecke: a que analisa a ação de imigrantes alemães. Seus escritos, como já aventamos, são em geral voltados para a cidade e seu entorno, sem a preocupação de sublinhar as questões étnicas. Na escrita da história produzida por ele, no entanto, um outro texto faz referência às questões da etnicidade em São Leopoldo. Trata-se do estudo sobre o colono alemão e o negro ${ }^{i i i}$ onde é destacada a presença de negros escravizados entre os imigrantes alemães. Tal texto enfoca, mesmo que de forma sutil, as diferenças étnicas na medida em que os 
escravizados aparecem nos inventários (40) de imigrantes de origem teuta e são indicados pelo seu valor pecuniário. Exemplo do que falamos é o registro do "escravo de menor valor" ser avaliado em 25\$000 em 1887.

Nesse contexto de destaque da etnia alemã na formação histórica de São Leopoldo, é mister aprofundar o papel e a participação de Germano Oscar Moehlecke na presidência da Comissão Municipal do Biênio da Colonização e Imigração. Seu relatório, ao final do período, dá conta das muitas atividades desenvolvidas no Município com o objetivo de destacar a etnia alemã no contexto do sesquicentenário. São inúmeras as ações de inauguração de escolas, Universidade [UNISINOS], parques, exposições. Algumas dessas realizações merecem destaque pela sua importância no conjunto das atividades planejadas. São realizações embasadas na memória e nas lembranças do passado, como a representação da chegada dos primeiros imigrantes a São Leopoldo pelo Rio dos Sinos. Esta apresentação reuniu a mais expressiva comitiva nacional representada pelo Presidente da República, Ernesto Geisel e filha, Ministros, Governadores, Prefeitos, Representantes da Alemanha e outras autoridades além do povo, que era a maioria. Este foi o dia mais importante do evento, e a cena representada reproduzia o imaginário da chegada dos antepassados, o que ajudava a manter uma imagem desse episódio que era comum a todos. Tal representação estava embasada na obra de Ernst Zeuner sobre "a chegada dos imigrantes alemães a São Leopoldo”. Essa apresentação teatral inspirada no quadro famoso nos levou a uma reflexão sobre os indivíduos que assistiam ao evento. Estes, representavam a memória, sempre cultivada, dos primeiros imigrantes. Catroga (2001), inspirado em Candau (2011), mostra-nos em seu texto que "não haverá memória coletiva sem suportes de memória ritualisticamente compartilhados. Ou seja, não haverá representação memorial sem traços" (CATROGA, 2001, p. 48). E a pintura, representada em forma teatral, reforçava esta memória.

Outra ação desenvolvida por essa comissão, liderada por Germano Moehlecke, foi a que buscou marcar o evento comemorativo dos 150 anos da imigração alemã com um monumento ao sesquicentenário, inaugurado no final do Biênio. Carregado de simbologia, o monumento quis representar, para além do passado, o caráter empreendedor do alemão que veio ocupar este lugar. Passado e presente eram lembrados neste monumento.

Uma terceira atividade da Comissão, entre muitas outras ocorridas em São Leopoldo nas comemorações do Biênio, foi a realização do I Simpósio de Imigração e 
Colonização Alemã. Esse evento é a semente do Instituto Histórico de São Leopoldo [IHSL] e do XXIII Simpósio de Imigração e Colonização que realizamos em 2018.

Tomando este evento pelo aspecto celebrativo, sabemos que ele é, antes de mais nada,

\begin{abstract}
uma atividade intrínseca à construção e à atualização de memórias, em meio a reafirmações e tensões. [...] Acontecimentos, passagens do tempo, processos fundantes são popularmente comemorados e celebrados nos dias festivos através de danças, ritmos, comidas, vestes, alegorias em representações lúdicas de marcantes experiências passadas e (re)memorizadas. (FERREIRA; SILVA; ANTONACCI, 2004, p. 9).
\end{abstract}

\title{
3. Como se dá a tessitura da história
}

Na década de 1990, Germano Oscar Moehlecke voltou ao seu tema preferido, escrevendo mais alguns livros sobre a sua cidade, entre os quais São Leopoldo, vida social e costumes, de 1997, e São Leopoldo obras e iniciativas públicas, de 1998. Ambos são edições do próprio autor e são resultantes, segundo suas palavras, de uma coleção de textos publicados em jornal, intitulada "Revivendo o Passado". São recortes esparsos, sobre diferentes ângulos da cidade e das suas gentes. Fragmentos da memória, diríamos. Neste mesmo contexto, destacamos também o livro publicado em 2011, São Leopoldo: retalhos de história, agora pela Editora Oikos, com contribuições à história da vida política e administrativa (1824-2010) de São Leopoldo. Acreditamos que este livro resultou de um encarte do jornal VS produzido algum tempo antes pelo mesmo autor. Em um outro capítulo, intitulado Trajetória de vida e produção historiográfica, publicado em obra organizada por Isabel C. Arendt e Marcos A. Witt (Org. $)^{\text {iv }}$, Germano Moehlecke falou com mais detalhes de sua produção, destacando que "nas crônicas procurou interpretar a vida e os sentimentos das pessoas" (2011b, p.85).

Tomando a obra de Germano Moehlecke como campo de análise, fazemos nossas as palavras de Rodrigues (2017), quando ele afirma que

segundo Walter Benjamin, o historiador deveria ser como um sujeito que recolhe os entulhos que a sociedade relega ao esquecimento. Sua tarefa deveria consistir em apropriar-se dos restos condenados ao lixo e deles fazer a matéria-prima de sua labuta. (RODRIGUES, 2017, p. 7).

Da mesma forma, o texto de Lucien Febvre (1989), citado por Rodrigues (2017), mostra-nos que trilhou caminho semelhante ao dizer que

Faz-se história, sem dúvida, com documentos escritos, quando eles existem; e até mesmo na sua falta, ela pode e deve fazer-se. A partir de tudo que a engenhosidade do historiador pode lançar mão para fabricar o seu mel, na falta de flores usuais. [...]. Em suma, a partir de tudo o que, pertencente ao homem, depende e está a serviço do homem, exprime o homem, significa a presença, a atividade, as preferências e as maneiras de ser do homem. (FEBVRE, 1989, p. 249, apud RODRIGUES, 2017, p. 7). 
Tais observações podem ser trazidas a lume em nossa análise, porque queremos ter presente o fato de estarmos tratando primeiramente da seleção das fontes históricas. Quando o autor que estudamos busca para sua análise somente os documentos publicados e/ou oficiais, ele está também ciente de que a escolha é sua e de que as fontes escolhidas são o primeiro passo para a escrita da história. É que cabe ao historiador/pesquisador recolher o que julgar pertinente para fazer os seus escritos. Portanto, somos nós pesquisadores/historiadores que, ao fazermos a nossa lista de coisas necessárias para um estudo de cunho histórico, nos defrontamos, num primeiro momento, com as muitas possibilidades de selecionar fontes, sejam elas bibliográficas, documentais ou formadas por objetos da cultura material. Como o pesquisador sempre tem alguma inquietação que o leva a questionamentos, para respondê-los obriga-se a organizar suas fontes listando-as e classificando-as. Este é o início do processo da escrita e, tal como um escritor ou um poeta, é sua a função de selecionar e organizar o conjunto documental, buscando respostas aos questionamentos formulados. Nesse primeiro quesito da análise, podemos dizer que a escolha das fontes de Moehlecke foram quase sempre de uma só matriz: a oficial. É desse lugar que olhamos a obra escrita por Germano Oscar Moehlecke para vê-lo como um homem que trabalhava, ou melhor, que buscava e se encantava com as fontes documentais sobre a história de São Leopoldo e as publicava a partir de algumas poucas perguntas, ou melhor, a partir de um propósito: chamar a atenção para os documentos existentes no Museu Histórico Visconde de São Leopoldo à disposição dos pesquisadores. Embora limitada no seu recorte analítico, esta operação historiográfica não invalidava seu trabalho. Ao contrário, ajudava aos pesquisadores na medida em que divulgava os documentos e indicava a sua localização. Nesse sentido podemos considerar Germano Oscar Moehlecke como um homem-fonte, ou seja, alguém que detém um saber e o repassa para aprendizes, para que possam continuar sua tarefa. Senão, vejamos: em seu primeiro livro, O Vale dos Sinos era assim (1978), encontramos, na orelha do mesmo que

[...] nota-se sempre a preocupação do autor pela verdade histórica da qual não se afasta de nenhuma forma mesmo quando dele se espera uma mais completa, e às vezes necessária, interpretação. Percebe-se esse cuidado pelas transcrições dos documentos originais, deixando o leitor completamente livre para ajuizar sobre o relatado" (orelha esquerda).

Noutro ponto do mesmo livro escreveu:

Quando estudamos a nossa história, todos os detalhes são interessantes. Daí a razão de publicarmos tantos episódios e acontecimentos do século passado [século 19], que fomos descobrindo nas nossas leituras no Arquivo do "Museu Histórico Visconde de São Leopoldo" (1978, p. 125, grifo nosso). 
Quando, na década de 1990, Germano Oscar Moehlecke iniciou a publicação do que ele chamou de uma espécie de coleção sobre São Leopoldo e que teve por subtítulo a expressão Revivendo o Passado, retirada de uma coluna com o mesmo nome no Correio de São Leopoldo, ele retomou a temática da vida social de São Leopoldo que já havia trabalhado noutros textos, descrevendo as festas, bailes, clubes, desfiles e outras atividades sociais que aconteciam na cidade até os anos de 1940. As fotografias ilustrativas de tais textos, ele as tomou como um rumo na escrita da história, pois as olhou como quem acredita que "a fotografia é uma fonte [...] que não deve ser subestimada" (MOEHLECKE, 1997, p.5).

Nossa análise fixa-se nesse recorte da memória de outros tempos e das festas de outrora para inserir uma questão sobre a produção de Germano Moehlecke, quando escreve tais livros. Essa produção pode ser vista como a produção de um memorialista? Ieda Gutfreind ao destacar o que entende por autores memorialistas étnicos diz:

Com esta expressão [memorialistas étnicos] identificamos pessoas que, do interior de seu
grupo étnico, escrevem sobre ele [...]. São indivíduos comprometidos com o seu grupo,
criando histórias do ponto de vista pessoal, familiar, com a colaboração de seus pares.
Publicam narrativas das respectivas coletividades, utilizando, ou não, outra
documentação que não a oral em suas pesquisas. São textos sempre (re)atualizados,
mantendo a linha mestra da rememoração (GUTFREIND, 2004, p. 30).

Tomando por base a definição de Gutfreind (2004) e aplicando-a aos livros inseridos na coleção Revivendo o Passado (livros que são fruto de escritos anteriores para o jornal) poderíamos enquadrar Moehlecke como um memorialista, mas ampliando a análise para a sua vasta produção, pensamos que ele não corresponde totalmente a este perfil, principalmente porque seu ponto forte, ao que nos foi dado observar e analisar, não foi a história oral ou a memória de seus pares. Foi a história da cidade em seus aspectos políticos, sociais, culturais. Buscou destacar aquilo que de mais rico julgou que a cidade possuía no Museu ou noutros lugares de memória: o seu acervo documental. É nesse contexto que a tessitura da história de São Leopoldo pode ser ampliada a partir da obra de Germano Oscar Moehlecke.

\section{Conclusão}

Os fragmentos que destacamos acima, de obras que analisamos mais detidamente, nos permitem pensar que para o autor a escrita da história só teria valor se fosse feita através de documentos originais, devidamente transcritos e cronologicamente arranjados. As fontes, tanto visuais quanto documentais, continham a verdade, para o 
autor. Ao mesmo tempo, as fotografias e as transcrições revelam sua preocupação com a divulgação dos documentos contidos no acervo do Museu Histórico Visconde de São Leopoldo, como já enfatizamos. É bem possível que Germano Moehlecke tenha sido o escritor que mais escreveu memórias sobre São Leopoldo. Ricas ilustrações e imagens acompanham seus textos, originalmente publicados em jornais locais e regionais.

Dar à luz "os aspectos mais diversos da memória social" da cidade foi um desejo e uma meta de Germano Moehlecke. A memória é retomada, ali e aqui para reafirmar que ela "só poderá desempenhar a sua função social através de liturgias próprias, centradas em reavivamentos que só os traços-vestígios do pretérito são capazes de provocar". (CATROGA, 2001, p. 48). Muito teríamos ainda a dizer sobre o nosso personagem, embora seja hora de deixá-lo. Ao fim e ao cabo, Germano Oscar Moehlecke pode ser considerado no todo de sua produção historiográfica e cultural como um defensor da memória e da cultura alemã em São Leopoldo. Ao longo de todo o tempo, vemo-lo como alguém que retoma as lembranças e as memórias para recriar ações que levassem a uma atitude de ligação com o passado, como foi o caso da criação do Museu Histórico Visconde de São Leopoldo [MHVSL] em 20 de setembro de 1959 e outras ações daí decorrentes.

\section{Referências}

ARENDT, Isabel C.; WITT, Marcos A. (Orgs.). Pelos caminhos da Rua Grande: história(s) da São Leopoldo republicana. São Leopoldo: Oikos, 2011.

CATROGA, Fernando. 'Memória e história'. In PESAVENTO, Sandra Jatahy. Fronteiras do milênio. Porto Alegre, Editora da UFRGS, 2001.

CANDAU, Joël. Memória e identidade. São Paulo: Contexto, 2011.

DIEHL, Astor Antônio. Cultura historiográfica: memória, identidade e representação. Bauru, SP: EDUSC, 2002.

FERREIRA, Jerusa Pires; SILVA, Marcos; ANTONACCI, Maria Antonieta (Orgs.). Projeto História (28) Revista de Estudos Pós-Graduados em História. PUC/SP, 2004, p. 9.

GOMES, Angela de Castro (Org.). Escrita de si, escrita da história. Rio de Janeiro: Editora FGV, 2004.

GUTFREIND, Ieda. A imigração judaica no Rio Grande do Sul. São Leopoldo: Editora Unisinos, 2004.

MOEHLECKE, Germano Oscar. O vale do Sinos era assim. São Leopoldo: Rotermund, 1978. 
MOEHLECKE, Germano Oscar. 'Quartel do $8^{\circ}$ BC'. In: INSTITUTO HISTÓRICO DE SÃO LEOPOLDO. Anais. São Leopoldo (vol. II), 1979/1981 e 1981/1983.

MOEHLECKE, Germano Oscar. Alemães na retomada de Porto Alegre. In: $6^{\circ}$ SIMPÓSIO DE HISTÓRIA DA IMIGRAÇÃO E COLONIZAÇÃO ALEMÃ̃S NO RIO GRANDE DO SUL. 1984. Anais. São Leopoldo: Instituto Histórico de São Leopoldo, 1984.

MOEHLECKE, Germano Oscar. Polêmica na comunidade evangélica de São Leopoldo. In: SIMPÓSIO DE HISTÓRIA DA IGREJA. São Leopoldo: Editora Sinodal, 1986.

MOEHLECKE, Germano Oscar. Os imigrantes alemães e a Revolução Farroupilha. São Leopoldo: s. e., 1986.

MOEHLECKE, Germano Oscar. Contribuição à história de Dois Irmãos. In: IV SIMPÓSIO DE HISTÓRIA DA IMIGRAÇÃO E COLONIZAÇÃO ALEMÃ NO RIO GRANDE DO SUL, 1980. Anais. São Leopoldo: Instituto Histórico de São Leopoldo, 1987.

MOEHLECKE, Germano Oscar. O colono alemão e o negro. In: VIII E IX SIMPÓSIOS DE HISTÓRIA DA IMIGRAÇÃO E COLONIZAÇÃO ALEMÃS NO RIO GRANDE DO SUL. 1988 E 1990. Anais... São Leopoldo: Instituto Histórico de São Leopoldo, 1988 e 1990.

MOEHLECKE, Germano Oscar. Uma estatística de Feitoria Velha em $1^{\circ}$ de julho de 1867. In: VIII E IX SIMPÓSIOS DE HISTÓRIA DA IMIGRAÇÃO E COLONIZAÇÃO ALEMÃS NO RIO GRANDE DO SUL. 1988 e 1990. Anais. São Leopoldo: Instituto Histórico de São Leopoldo, 1988 e 1990.

MOEHLECKE, Germano Oscar. Vida social e costumes. São Leopoldo: s/e, 1997 (Coleção Revivendo o passado, 1)

MOEHLECKE, Germano Oscar. Obras e iniciativas públicas. São Leopoldo: s/e, 1998. (Coleção Revivendo o passado, 2)

MOEHLECKE, Germano Oscar. São Leopoldo: retalhos de história. São Leopoldo: s/e, 2000a. (Coleção Revivendo o passado, 3)

MOEHLECKE, Germano Oscar. Uma defesa que conta a história. In: VII SIMPÓSIO DE HISTÓRIA DA IMIGRAÇÃO E COLONIZAÇÃO ALEMÃS NO RIO GRANDE DO SUL (7: 1986: São Leopoldo). Anais. São Leopoldo, 1986. Nova Petrópolis: Editora Amstad, 2000b.

MOEHLECKE, Germano Oscar. Estrada de ferro - contribuição para a história da primeira ferrovia do Rio Grande do Sul. São Leopoldo: Rotermund, 2004.

MOEHLECKE, Germano Oscar. Aos vinte e cinco anos da imigração: os números falam pela história. In: XI SIMPÓSIO DE HISTÓRIA DA IMIGRAÇÃO E COLONIZAÇÃO, 2009. 170 anos de imigração alemã. São Leopoldo: Oikos, 2009. 1 CD-ROM.

MOEHLECKE, Germano Oscar. 'O Professor Dr. Martin N. Dreher e o Instituto Histórico de São Leopoldo'. In: MÜGGE, Miquéias Henrique; MÜGGE, Erny; HAUENSTEIN, Iria (Orgs.). Construindo diálogos. História, educação e ecumenismo. Homenagem a Martin N. Dreher. São Leopoldo: Oikos, 2010, p. 231-232.

MOEHLECKE, Germano Oscar. São Leopoldo: contribuição à história da vida política e administrativa (1824-2010). São Leopoldo: Oikos, 2011a. 
MOEHLECKE, Germano O. Trajetória de vida e produção historiográfica. In: ARENDT, Isabel C.; WITT, Marcos A. (Orgs.). Pelos caminhos da Rua Grande: história(s) da São Leopoldo republicana. São Leopoldo: Oikos, 2011b, p. 83-87.

MOEHLECKE, Germano. A Câmara ao longo dos tempos. In: SILVA, Haike Roselane Kleber da; HARRES, Marluza Marques (Orgs.). A história da Câmara e a Câmara na história. São Leopoldo: Oikos, 2006, p. 25 -44.

PESAVENTO, Sandra Jatahy (Org.). Fronteiras do milênio. Porto Alegre: Ed. Universidade/UFRGS, 2001.

REIS, José Carlos. As identidades do Brasil: de Varnhagen a FHC. Rio de Janeiro: Editora FGV, 1999.

RODRIGUES, Rogério Rosa (Org.) LIEBEL, Silvia, (et al). Possibilidades de pesquisa em história. São Paulo: Contexto, 2017.

SILVA, Haike Roselane Kleber da. HARRES, Marluza Marques (Orgs.). A história da Câmara e a Câmara na história. São Leopoldo: Oikos, 2006.

WEBER, Roswithia. A criação de um museu de imigração alemã no pós-nacionalização. Revista Memória em Rede, Pelotas, v.3, n.9, Jul/Dez. 2013 - ISSN- 2177-4129. Disponível em: <www.ufpel.edu.br/ich/memoriaemrede>. Acesso em: set. 2018.

WEBER, Roswithia. 'Pré-história do museu - III o papel do museu no reavivamento étnico'. In: EGGERS, José Carlos; LINK, Márcio et al. Museu Histórico Visconde de São Leopoldo - 50 anos de história. Novo Hamburgo: Um Cultural, 2012.

Recebido: 22/02/2019

Aceito: 05/04/2019

Publicado: 13/05/2019

\footnotetext{
i Doutora (2005) em História pela Universidade do Vale do Rio dos Sinos - UNISINOS. Vinculada ao Curso de Letras da UNISINOS, assim como ao Curso de História do Instituto Superior de Educação Ivoti [Instituto Ivoti]. E-mail: isabel_arendt@hotmail.com

ii Doutora em História pela Universidade Federal do Rio Grande do Sul. Professor Adjunto II da Universidade do Vale do Rio dos Sinos. E-mail: eloisa@unisinos.br

iii Este texto foi publicado nos Anais do VIII Simpósio de História da Imigração e Colonização Alemã no Rio Grande do Sul, o qual foi realizado em 1988, p.56 -65.

${ }^{\text {iv }}$ A temática sobre São Leopoldo esteve presente em outros trabalhos do autor como: MOEHLECKE Germano O. Estrada de ferro: contribuição para a história da primeira ferrovia do Rio Grande do Sul. São Leopoldo, Rotermund, 2004. Além destas obras, encontramos um bom número de trabalhos em Simpósios e Seminários de que o autor participou, entre os quais citamos: MOEHLECKE Germano O. Polêmica na comunidade evangélica de São Leopoldo. SIMPÓSIO DE HISTÓRIA DA IGREJA, 1986. O texto foi publicado pela Editora Sinodal neste mesmo ano; __ . Contribuição à história de Dois Irmãos apresentado no IV SIMPÓSIO DE HISTÓRIA DA IMIGRAÇÃO E COLONIZAÇÃO ALEMÃ NO RIO GRANDE DO SUL no ano de 1980 e publicado nos Anais do IHSL, no ano de 1987; . Quartel do $8^{\circ}$ BC, publicado no vol. II dos Anais do IHSL nos anos de 1979/1981 e 1981/1983. Alemães na retomada de Porto Alegre. VI SIMPÓSIO DE HISTÓRIA DA IMIGRAÇÃO E COLONIZAÇÃO ALEMÃS NO RIO GRANDE DO SUL 1984, publicado nos Anais do IHSL no mesmo ano; ___ . O colono alemão e o negro, VIII E IX SIMPÓSIOS DE HISTÓRIA DA IMIGRAÇÃO E COLONIZAÇÃO ALEMÃS NO RIO GRANDE DO SUL, 1988 e 1990. Anais do IHSL em 1988 e 1990.__. Uma estatística da Feitoria Velha em $1^{\circ}$ de julho de 1867. VIII E IX SIMPÓSIOS DE HISTÓRIA DA IMIGRAÇÃO E COLONIZAÇÃO ALEMÃS NO RIO GRANDE DO SUL. 1988 e 1990 publicado nos Anais do IHSL em 1988 e 1990; Uma defesa que conta a história. VII SIMPÓSIO DE HISTÓRIA DA IMIGRAÇÃO E COLONIZAÇÃO ALEMÃS NO RIO GRANDE DO SUL, 1986. Publicado pela Editora Amstad, 2000.__. Aos vinte e cinco anos da imigração: os números falam pela história, apresentado no XI SIMPÓSIO DE HISTÓRIA DA
} 
IMIGRAÇÃO E COLONIZAÇÃO, em 2009. 170 anos de imigração alemã. São Leopoldo: Oikos, 2009. 1 CD-ROM; ___ _ O Professor Dr. Martin N. Dreher e o Instituto Histórico de São Leopoldo. In: MÜGGE, Miquéias Henrique; MÜGGE, Erny; HAUENSTEIN, Iria (Orgs.). Construindo diálogos.

História, educação e ecumenismo. Homenagem a Martin N. Dreher. São Leopoldo: Oikos, 2010, p. 231 232. 